Approach for conbi ni ng physi cal properti es and sensi bi l ity for pl easant beverage can- openi ng sound

\begin{tabular}{|l|l|}
\hline 著者 & $\begin{array}{l}\text { Komat suzaki Toshi hi ko, Han Ji ng, Uchi da } \\
\text { H r oaki }\end{array}$ \\
\hline $\begin{array}{l}\text { j our nal or } \\
\text { publ i cat i on ti tl e }\end{array}$ & Appl i ed Acoust i cs \\
\hline vol une & 103 \\
\hline page r ange & $64-70$ \\
\hline year & $2016-02-01$ \\
\hline URL & ht t p: //hdl . handl e. net /2297/43919 \\
\hline
\end{tabular}




\title{
Approach for Combining Physical Properties and Sensibility for Pleasant Beverage Can-opening Sound
}

\author{
Toshihiko Komatsuzaki ${ }^{\mathrm{a}, *}$, Jing Han ${ }^{\mathrm{b}}$, Hiroaki Uchida ${ }^{\mathrm{b}}$ \\ ${ }^{a}$ Kanazawa University, Institute of Science and Engineering, Kakuma-machi, Kanazawa, \\ Ishikawa, 920-1192 Japan \\ ${ }^{b}$ Universal Can Corporation, 1500 Suganuma, Oyama-cho, Sunto-gun, Shizuoka, \\ 410-1392 Japan
}

\begin{abstract}
The sound quality of consumer products has recently become an important feature, receiving much attention in the fields of engineering and manufacturing. The sound could add value to the product in the way that it meets the interests and preferences of consumers in a wide range of fields. The present study deals with the sound emitted from beverage cans when lifting the tab of the can end to open it before drinking. With a view toward finding the characteristics of sound that have a sense of ease and certainty for the consumer when opening a beverage can, we introduce the semantic differential method for the subjective assessment of sounds of various cans. We then perform waveform analyses in both time and frequency domains to determine the physical properties of the desirable sounds. Finally, we successfully correlate the texture factor with the duration of the tearing sound, which may be a new way to design cans with pleasant sounds.
\end{abstract}

Keywords: Sound design, Beverage can, Semantic differential method, Frequency analysis

\section{Introduction}

A product's intrinsic sound is considered to be a significant factor in the characterization of its image and quality, and it may provide satisfaction to the consumer [1]. For example, the sound heard when opening a beer can

\footnotetext{
*Corresponding author. Tel.: +81 76234 4673; fax: +81 762344676 .

Email address: toshi@se.kanazawa-u.ac.jp (Toshihiko Komatsuzaki)
} 
could give consumers a pleasant feeling so that they might be disposed to drink the beverage. The sound heard when closing an automobile's door is designed to project a sense of luxury $[2,3]$. We subconsciously realize that a photograph was taken when we hear the "snapshot" sound of a digital camera, even though the sound is not necessary for the camera to function [4]. These examples show that a characteristic sound has the ability to add special meaning to a product. Past studies of sound control technology focused mainly on the mitigation of unwanted noises in products, such as those of vacuum cleaners and air conditioners [5]. Recently, attempts have been made to design pleasant and more appealing sounds to give a sense of luxury and quality to a product to meet the preferences of each individual [6]-[8]. The designed sounds could enhance the value and attractiveness of a product.

The unique sound emitted when opening a beverage can could affect consumer sentiment. There have been several studies on the ergonomic design of easy-to-open, easy-to-grasp, easy-to-drink, and scented aluminum beverage cans and bottles [9]-[12], but literatures on the design of the can-opening sound are not found.

The aim of the present study was to develop a design procedure to realize an expected can-opening sound, by which the semantic space obtained by evaluation of the sensibility for the can-opening sound correlates with the physical properties of the sound. First, we defined the goal of the design of the can-opening sound as "a sound that brings to the user an easy-to-open, comfortable feeling with sureness." To evaluate sensibility, we introduced a semantic differential (SD) scale method, a technique that uses a rating scale to measure the meaning of objects and concepts. At the same time, we evaluated the physical properties by using time series analysis, frequency analysis, and loudness and sharpness assessments. These investigations were followed by a correlation analysis that studied the relationship between the psychological factors and the physical parameters. Finally, based on the correlation analysis, we determined the design parameters of the beverage can, such as its geometrical and acoustical features, that can be physically altered to achieve the goal of a pleasant sound.

\section{Materials and Methods}

\subsection{Sensibility evaluation using the SD method}

The SD method is a psychological measurement technique that identifies the connotative meaning of objects and concepts. The method has drawn 


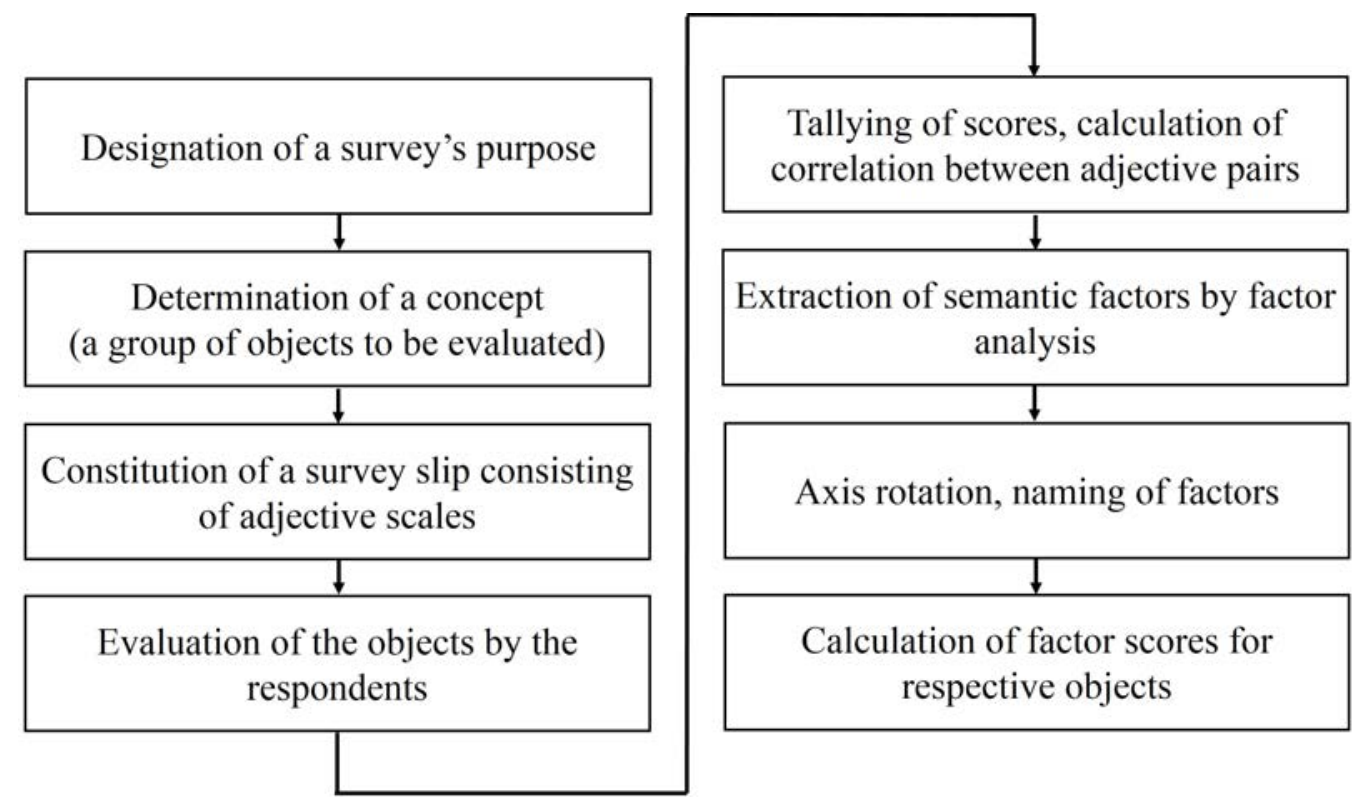

Figure 1: General workflow used in the SD method.

attention for use in sensibility analysis of objects since it was first developed by Osgood in the 1950s [13]. The SD method measures an individual's impression or the perceived meaning of an object by using a series of adjective scales. The adjective scale is a bipolar rating scale that typically has seven choices between a bipolar adjective pair, the components of which have opposite meanings. The obtained scores undergo factor analysis to extract the dimension of semantic space for the object. The general workflow of the SD method is shown in Fig.1.

We selected 14 adjective pairs suitable for sound evaluation to form the survey's scales. The adjective scales were then used within the SD evaluation framework to rate the can-opening sounds. In addition, three factor axes were extracted from the obtained scores via factor analysis to form a semantic space that explains the connotative meaning of the sound.

\subsection{Selection of adjective pairs for sound evaluation}

The selection of appropriate adjective pairs is the important first step in successful factor analysis in the SD method. The components of an adjective pair are at the ends of the rating scale and have opposite meanings (e.g., strong - weak and long - short). In the present study, we started with 25 
adjective pairs that we obtained by referring to past work on sound evaluation [14]. We then reduced the number of adjective pairs to 12 by merging similar pairs that overlapped in their meanings, thereby avoiding fatigue and boredom of the respondents. The 12 pairs were chosen as follows: First, we selected four can-opening sounds, two for carbonated and two for noncarbonated beverages. Second, after listening to the four can-opening sounds that were presented in sequence, 14 male university students, ranging in age from 22 to 24 years, chose 12 out of the 25 adjective pairs that they thought were suitable for evaluating the can-opening sound. The respondents could listen to the sounds as many times as necessary.

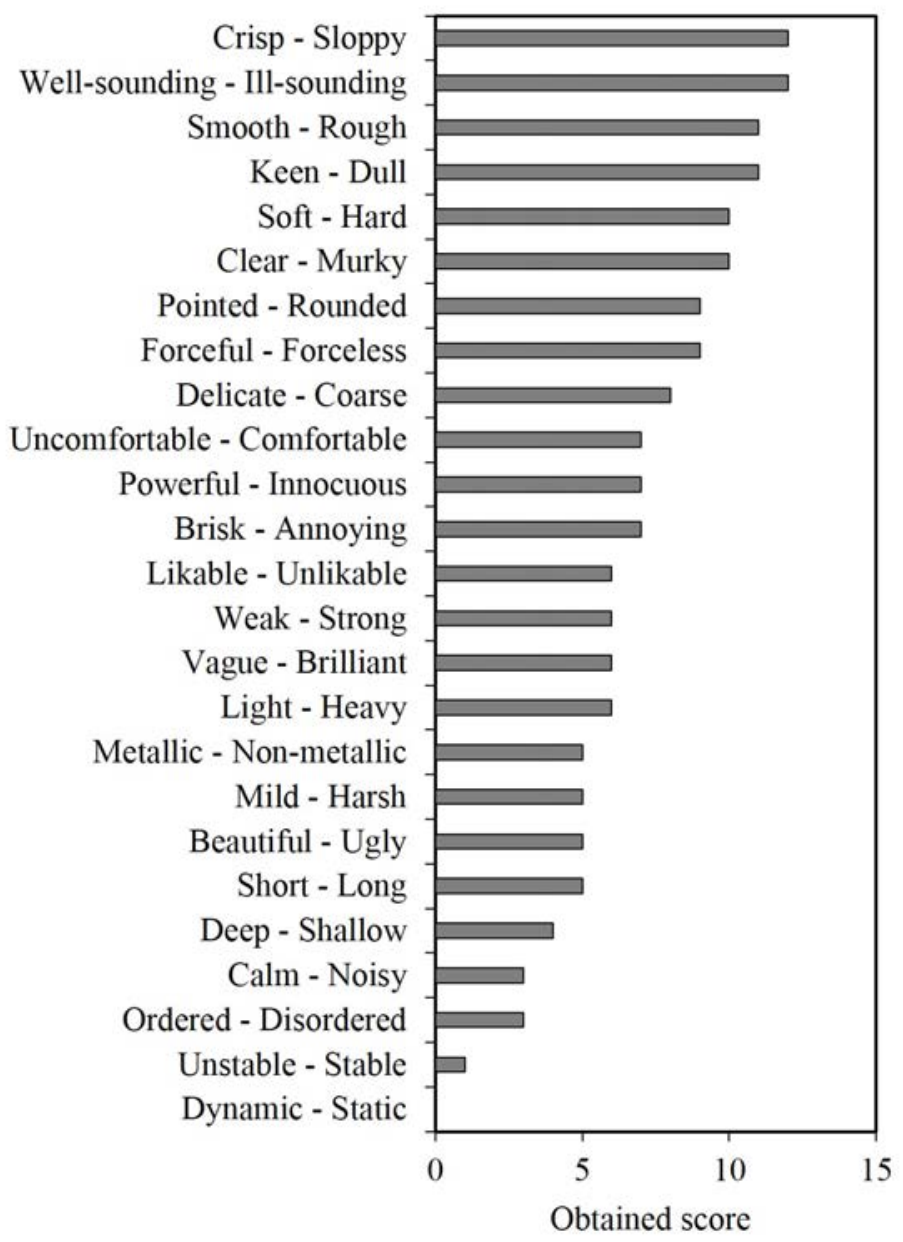

Figure 2: Rating of adjective pairs in the preliminary test. 
Table 1: Adjective pairs selected for the subjective evaluation of sounds.

\begin{tabular}{|c|c|}
\hline 1. Delicate-Coarse & 8. Well-sounding-Ill-sounding \\
\hline Smooth-Rough & Keen-Dull \\
\hline Clear-Murky & Powerful-Innocuous \\
\hline Forceful-Forceless & Crisp-Sloppy \\
\hline 5. Hard-Soft & 12. Comfortable-Uncomfortable \\
\hline 6. Pointed-Rounded & 13. Wiggling-Bursty \\
\hline Brisk-Annoying & Secure-Insecure \\
\hline
\end{tabular}

The 25 adjective pairs presented to the respondents are listed in Fig.2, along with their scores shown as bar graphs. In addition to the top 12 adjective pairs, an additional two pairs were introduced to evaluate the sensibility of sounds that could express the objective sound features Wiggling - Bursty and Secure - Insecure. The 14 pairs used for the following analysis are listed in Table 1.

\subsection{Sensibility evaluation using the SD technique}

Next, the sensibility for can-opening sounds was evaluated by the respondents using the 14 adjective pairs determined in the previous subsection. Evaluations were made as follows: Eleven male university students, between the ages of 22 and 24 years, listened to the sound of eight noncarbonated (cans A-H) and eight carbonated (cans I-P) $350 \mathrm{ml}$ stay-on-tab-type beverage cans as they opened each can. The evaluations were made in an ordinary meeting room without sound proofing treatment, where the background noise level was approximately 40dB. Each time the respondents opened a can, the can-opening sound was recorded using an IC recorder (SONY PCM-D50) placed $30 \mathrm{~cm}$ apart from the can. The respondents were asked to open the can within approximately $2 \mathrm{~s}$. After a respondent opened a can, he provided scores for the 14 adjective pairs, each of which was divided into a five-step scale. The respondents also scored the recordings, which they could listen to as many times as necessary.

Specific part names of an aluminum beverage can end are explained in Fig.3. As shown in Fig.4, cans were grouped by the score geometry on can end. Cans A, F, H, and O had relatively narrow scores; B, D, G, I, K, N, and $\mathrm{P}$ had middle-size scores; and $\mathrm{C}, \mathrm{E}, \mathrm{J}, \mathrm{L}$, and $\mathrm{M}$ had wide scores. 


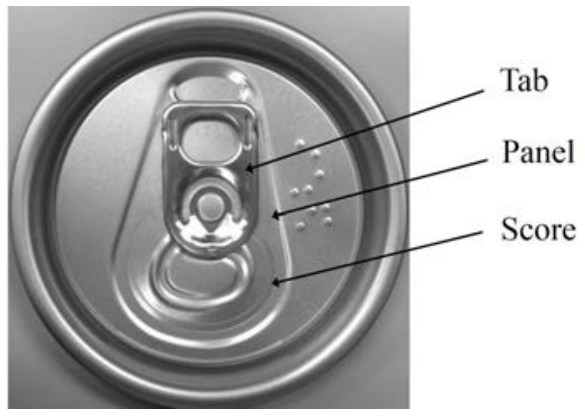

Figure 3: An aluminum beverage can end showing its part names.

(a)

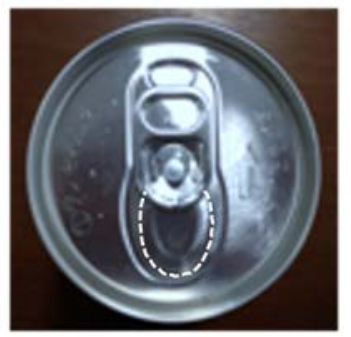

(b)

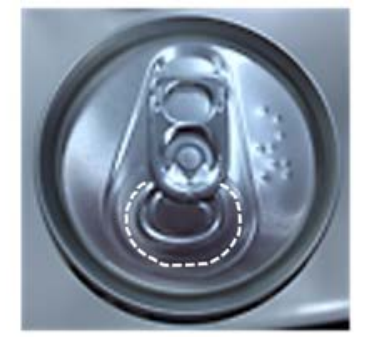

(c)

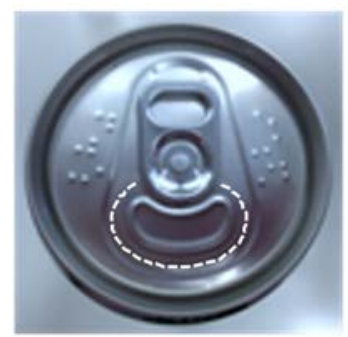

Figure 4: Sample cans were grouped by the score geometry. Photographs are shown for (a) sample can A with a narrow score, (b) can B with a middle-size score, and (c) can C with a wide score. Broken line shows score line of each can end.

The tallied scores were then put into the SD scale calculation. The correlation coefficients between all possible adjective pairs were calculated using the scores obtained for each pair in the sensibility evaluation. Next, the adjective pairs that had similar connotative meaning were grouped using factor analysis [15], i.e., the grouping was based on the collection of adjective pairs that had the largest factor loadings on the same factor axis, which is used to map connotative space structure visually onto two- or three-dimensional orthogonal space.

\subsection{Measurement and analyses of the physical properties of can-opening sounds}

The several analyses were conducted to extract the physical properties of the recorded can-opening sounds to understand the characteristics of the samples. Another purpose of the investigation was to find a common physical feature among cans B, D, I, and K, which received the highest scores in the sensibility analysis and were thought to approximate the objective can- 


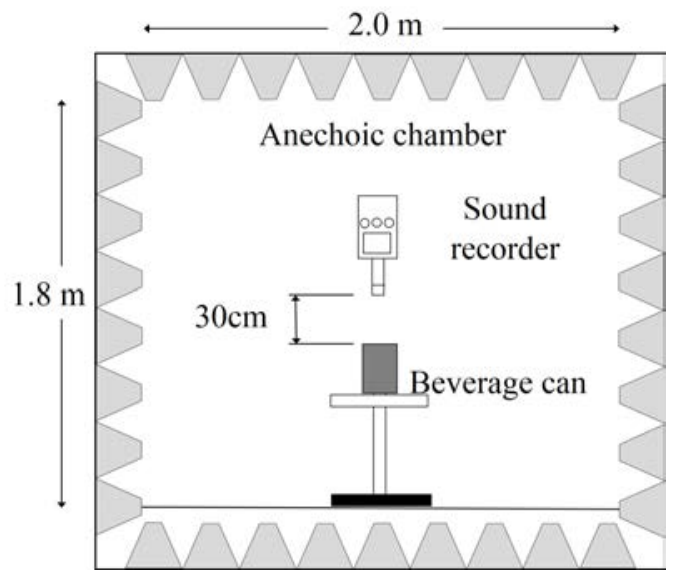

Figure 5: Schematic of can-opening sound measurement system.

opening sound. The physical properties were chosen in such a way that strong association with the strength and texture factors was expected and that each could be expressed by a single quantity. As shown in Fig.5, the can-opening sounds were measured using a sound recorder (SONY PCMD50) in an anechoic chamber. The recorder was fixed to a stand and kept $30 \mathrm{~cm}$ from the subject cans.

In the sound recording for the physical analysis, the uncertainty in the way of opening cans that might influence the can-opening sounds was removed as far as possible. The cans were always opened by the same operator, who had been trained to open cans almost at the same condition. In this way, nearly the identical waveform of the sound could be obtained for the same product.

The recorded sounds were analyzed using acoustic analysis software (PsySound3, developed by Cabrera et al. [16]) to obtain both physical and psychoacoustic parameters. The physical analysis of the sounds included timeseries analysis, frequency analysis, and octave-band sound level analysis. In addition, loudness and sharpness underwent psychoacoustic analysis. The loudness parameter of a sound causes humans to have a strong impression of it and its value tends to increase with sounds of frequency between 2 and $4 \mathrm{kHz}$. On the other hand, the sharpness parameter is the shrillness of a sound, where the high pitch sounds metallic to the listener. The test sample cans used here were the same as those used in the sensibility analysis.

An example of the time-history waveform of the sound of a can being opened is shown in Fig.6. The time-history waveform has two parts. The 


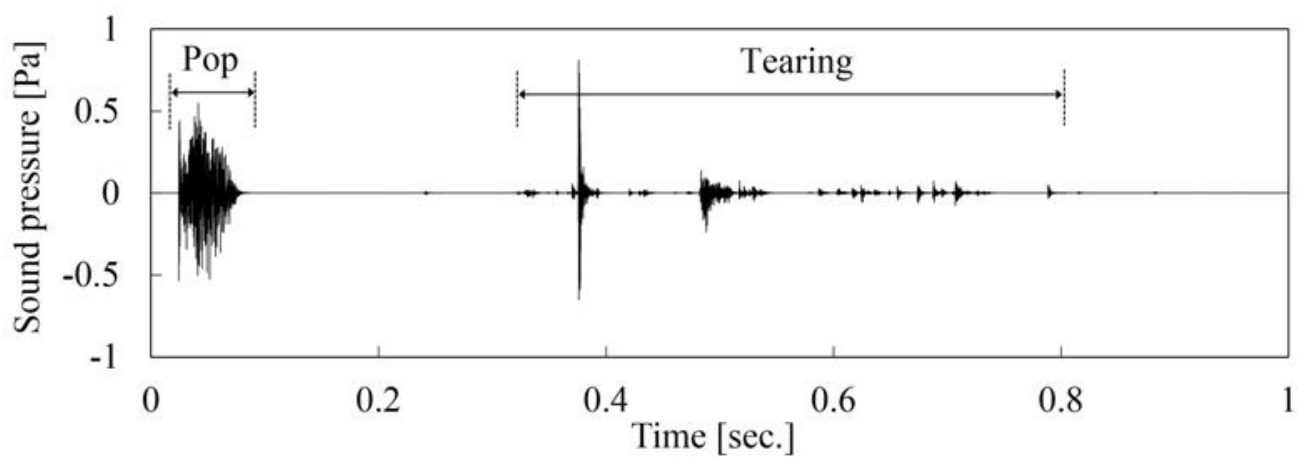

Figure 6: An example of the time history of a can-opening sound (sample can B).

first part is the pop sound, which is a mixture of two impulsive sounds: one is emitted when the scored piece of the can's top begins to crack and the other is outgassing from the container. The second part of the waveform is the tearing sound that occurs while the scored top continues to be cracked until the can is completely opened.

We evaluated the duration of the pop and tearing sounds $\left(T_{\mathrm{p}}\right.$ and $\left.T_{\mathrm{t}}\right)$, the peak values of their loudness $\left(L_{\mathrm{p}}\right.$ and $\left.L_{\mathrm{t}}\right)$, their sharpness values $\left(S_{\mathrm{p}}\right.$ and $\left.S_{\mathrm{t}}\right)$, and their peak frequency $\left(f_{\mathrm{p}}\right.$ and $\left.f_{\mathrm{t}}\right)$ using frequency analysis. The definitions of these values are shown in Fig.7. Loudness was calculated according to the definition in ISO 532 [17]. In the figure, sone is a unit used to scale loudness level, where 1 sone is equivalent to the loudness level of a $1 \mathrm{kHz}$ tone at 40 $\mathrm{dB}$ SPL. Loudness value was then used to estimate the sharpness using the following formula:

$$
S=0.11 \times \frac{\int_{0}^{24 \mathrm{Bark}} N^{\prime} g^{\prime}(z) d z}{\int_{0}^{24 \mathrm{Bark}} N^{\prime} d z}
$$

where $N^{\prime}$ is the loudness density, $g^{\prime}(z)$ is the weight function, and $z$ is the critical band rate. The term 'Bark' indicates the Bark scale critical band proposed by Zwicker [18]. The Bark scale consists of 24 auditory critical bands that correspond to the $0-15.5 \mathrm{kHz}$ frequency range. A frequency $f$, in $\mathrm{kHz}$, is converted into a Bark scale value as follows:

$$
\text { Bark }=13 \times \tan ^{-1}(0.76 f)+3.5 \times \tan ^{-1}\left\{(f / 7.5)^{2}\right\}
$$

The weight function $g^{\prime}(z)$ in Eq. (1) is further defined as 
(a)

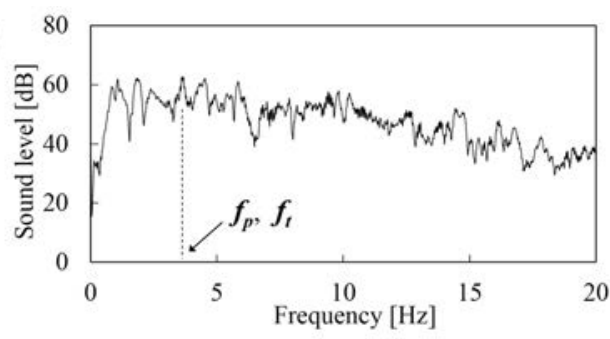

(b)

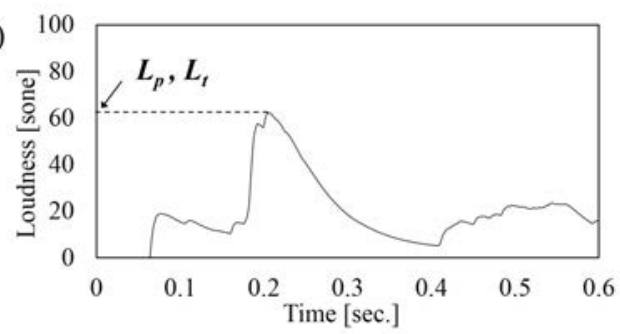

(c)

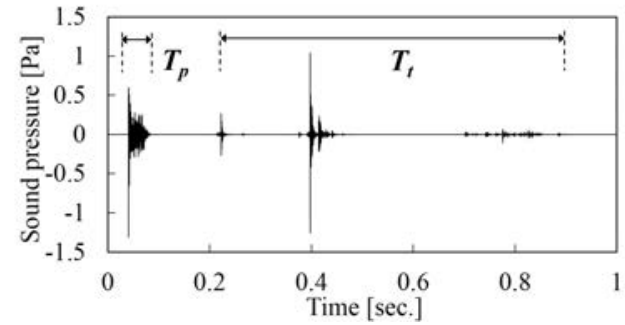

Figure 7: Definition of the physical properties of the pop and tearing parts of the canopening sound: (a) the peak frequency $f_{\mathrm{p}}$ and $f_{\mathrm{t}}$, (b) the peak loudness $L_{\mathrm{p}}$ and $L_{\mathrm{t}}$, and (c) the duration of opening sounds, $T_{\mathrm{p}}$ and $T_{\mathrm{t}}$, in the time history.

$$
g^{\prime}(z)= \begin{cases}1 & z<14 \\ 1+0.003 \times(z-14)^{3} & z \geq 14\end{cases}
$$

As seen in Eq. (1), sharpness is defined as the ratio of the weighted and the nonweighted integral of the loudness density, for which the acum is used as a unit of measure. The weighting factor, calculated using Eq. (3), is shown in Fig.8. It is known that the weighting increases as the critical band rate increases, so that the estimated sharpness is large for high-frequency sound.

\section{Results and Discussion}

\subsection{Factor analysis results}

In this subsection, we discuss the results of the sensibility evaluation of the can-opening sounds by the respondents. Among the adjective pairs that were thought to be suitable for assessing the conformity of the can-opening sound with the objective sound, the combination of Smooth - Rough, Crisp - Sloppy, and Wiggling - Bursty highlighted the difference of cans, and their scores, averaged over every sample, are shown in Fig.9. Cans B, D, I, and $\mathrm{K}$ were thought to have nearly ideal can-opening sounds since they had the highest scores for these adjective pairs compared to the rest of the cans. 


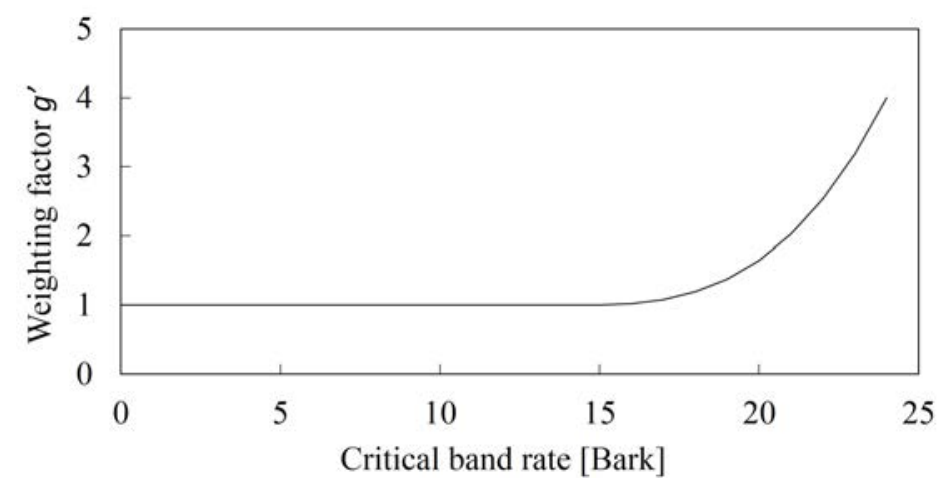

Figure 8: Weighting function $g^{\prime}(z)$ used in calculating sharpness.

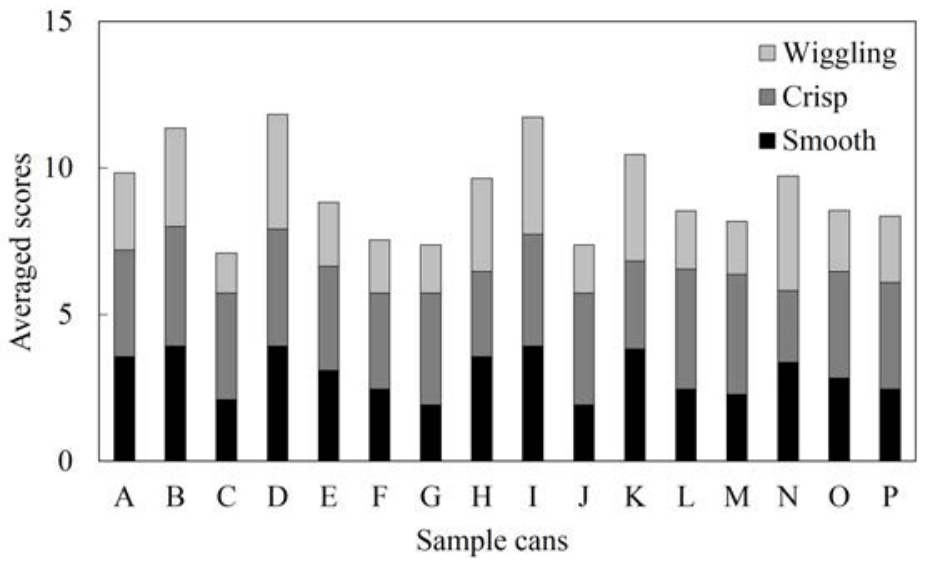

Figure 9: Examples of the averaged adjective scores obtained by subjective evaluation.

The adjectives were divided into three semantic factor groups, "strength," "texture," and "comfort," using their factor-loading values, and each factor was labeled with an intrinsic name that came from the member adjectives of the group. Table 2 presents the three factors obtained in the present analysis. The adjective pairs in each group more or less correlate with each other. In addition, the factor scores for respective sample cans were calculated using the factor-loading values and are schematically plotted in Fig.10, where the three possible combinations of the three factors are used for the two axes in two-dimensional coordinate space. Figures 10(a) and 10(c) show that the opening sounds of cans B, D, I, and K have the highest scores in the texture factor. Therefore, the semantic feature of the target can-opening 
Table 2: Factor loadings of adjective pairs divided into three factor groups obtained by factor analysis.

\begin{tabular}{cccc}
\hline & \multicolumn{3}{c}{ Factors } \\
\cline { 2 - 4 } & Strength & Texture & Comfort \\
\hline Well-sounding & 0.867 & 0.028 & 0.428 \\
\hline Keen & 0.849 & -0.416 & 0.068 \\
\hline Forceful & 0.805 & -0.520 & -0.037 \\
\hline Crisp & 0.802 & -0.101 & 0.121 \\
\hline Powerful & 0.768 & -0.411 & 0.075 \\
\hline Hard & 0.562 & -0.538 & -0.497 \\
\hline Delicate & -0.718 & 0.519 & 0.334 \\
\hline Smooth & -0.219 & 0.936 & 0.109 \\
\hline Wiggling & -0.283 & 0.895 & -0.088 \\
\hline Pointed & 0.278 & -0.914 & -0.160 \\
\hline Comfortable & 0.032 & 0.275 & 0.949 \\
\hline Secure & 0.108 & 0.168 & 0.929 \\
\hline Brisk & 0.119 & -0.141 & 0.834 \\
\hline Clear & 0.492 & -0.213 & 0.445 \\
\hline
\end{tabular}

sound is thought to be strongly related to the texture factor. On the other hand, the strength and comfort factors are less likely to correlate with the objective sound because these scores for every can were highly variable within the plane [Fig. 10(b)], irrespective of the characteristic of each can-opening sound.

The expected opening sound may be decided by designers considering various factors such beverage, drinking seasons, drinking places, target consumers and so on. In the present study, the young males were assumed as target consumers and eleven qualified students were selected to participate in the sensitivity evaluation. For the enhanced statistical reliability, the number of subjects should be increased. However, toward a specific goal, narrowing down the target consumers may be effective in order to avoid the sensibility analysis becomes diffusive.

\subsection{Physical and psychoacoustic analyses of can-opening sounds}

Loudness $L_{\mathrm{p}}$ and $L_{\mathrm{t}}$, sharpness $S_{\mathrm{p}}$ and $S_{\mathrm{t}}$, peak frequencies $f_{\mathrm{p}}$ and $f_{\mathrm{t}}$, and duration of sound, $T_{\mathrm{p}}$ and $T_{\mathrm{t}}$, for 16 sample cans are plotted in two- 
(a)

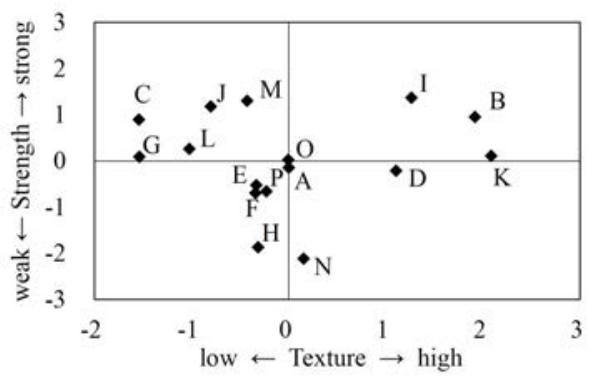

(b)

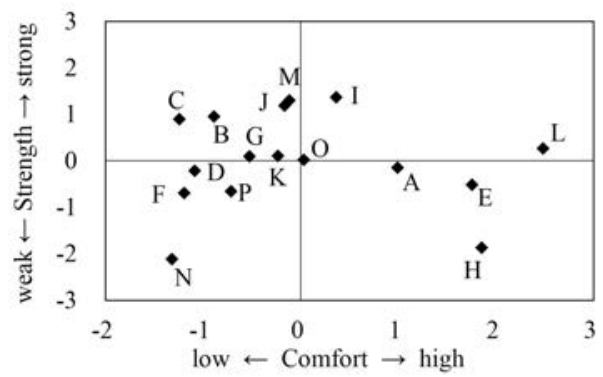

(c)

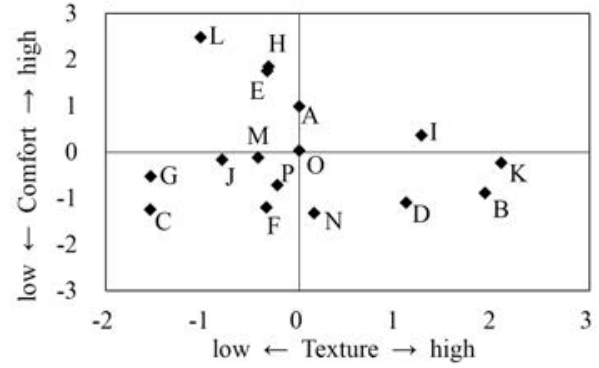

Figure 10: Distribution of factor scores for can-opening sounds of each can: (a) strength factor vs. texture factor, (b) strength factor vs. comfort factor, and, (c) comfort factor vs. texture factor.

dimensional planes in Fig. 11(a)-11(d), respectively. Although these results were from the recorded can-opening sounds, where all the cans in the figure were opened by the same person, a constant opening speed was not maintained. Therefore, the durations obtained for the pop and tearing parts were normalized by the total can-opening time. In addition, because the preliminary test revealed that there is little difference in the waveforms of the emitted sound between the same sample cans, only one typical example was analyzed for each sample and no averaging was performed.

Figure 11(a) shows that $L_{\mathrm{t}}$ was usually greater than $L_{\mathrm{p}}$ for all samples. Loudness waveforms of the pop sound for sample cans B and $J$ are shown in Fig. 12(a) and 12(b), and waveforms of the tearing sound are shown in Fig. 12(c) and 12(d), respectively. The pop sound is mainly the blowing sound of a gas, which has a broadband frequency component, and the tearing sound is primarily the sound of metallic fracture propagation, which has a narrowband frequency component. $L_{\mathrm{p}}$ and $L_{\mathrm{t}}$ vary considerably among the samples and there does not seem to be any correlation with each other. The loudness waveforms of the tearing sound are classified roughly into two groups, one with a series of waves of moderate amplitude, as in Fig. 12(c), 
(a)

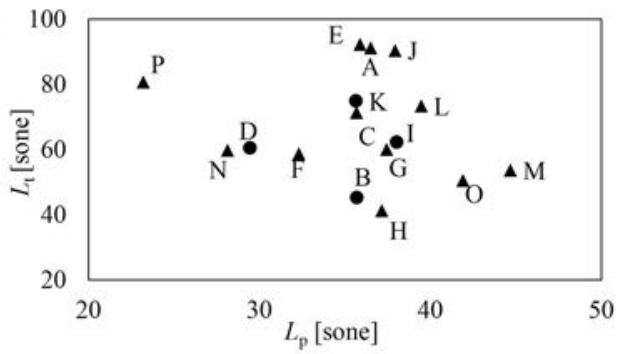

(c)

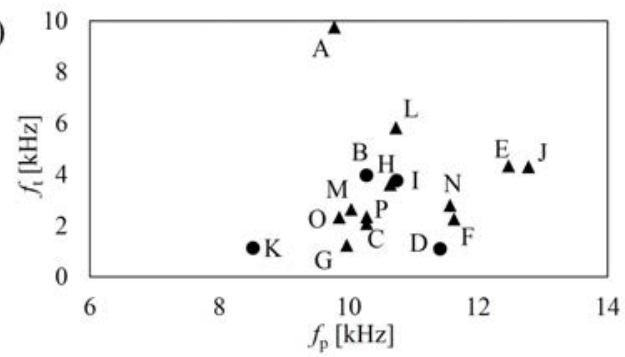

(b)

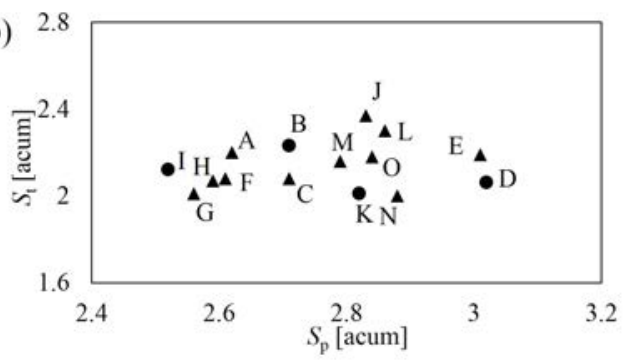

(d)

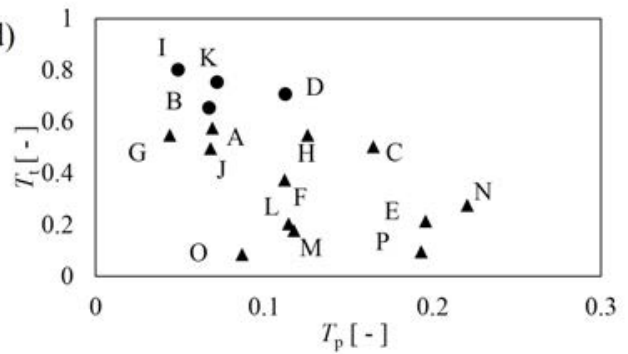

Figure 11: The physical and the psychoacoustic parameters extracted from the pop and tearing parts of the respective can-opening sounds: (a) peak values of loudness, $L_{\mathrm{p}}$ and $L_{\mathrm{t}}$, (b) sharpness values $S_{\mathrm{p}}$ and $S_{\mathrm{t}}$, (c) peak frequencies $f_{\mathrm{p}}$ and $f_{\mathrm{t}}$, and (d) durations of sound, $T_{\mathrm{p}}$ and $T_{\mathrm{t}}$. $(\boldsymbol{\Lambda})$ Single loudness peak, $(\bullet)$ multiple loudness peaks.

and one with only one wave of large amplitude, as in Fig. 12(d). This characteristic difference is the result of the fracture mechanisms along the score line, where the fracture propagates intermittently along the score line or at once. Figure 11(b) shows that the pop sound seems metallic to humans because its sharpness value is always larger than that of the tearing sound in all samples. Furthermore, Fig. 11(c) shows that the peak frequencies of all the pop sounds are in a high-frequency region of $10.7 \mathrm{kHz}$ on average, and that of the tearing sounds are in a relatively low-frequency region of 3.35 $\mathrm{kHz}$ on average. Finally, Fig. 11(d) shows that the duration of the tearing sound as a proportion of the total time to open the can varied significantly among the samples. The two symbols in Fig. 11(d) correspond to the two time-dependent loudness features in Fig. 12(c) and 12(d).

Sensibility analysis found that sample cans B, D, I, and K had the objective sound characteristics. The results discussed above are summarized below, with a focus on those sample cans:

1. There are several local maxima in the time histories of the loudness of the tearing sounds. Three local maxima were found for samples B, I, 
(a)

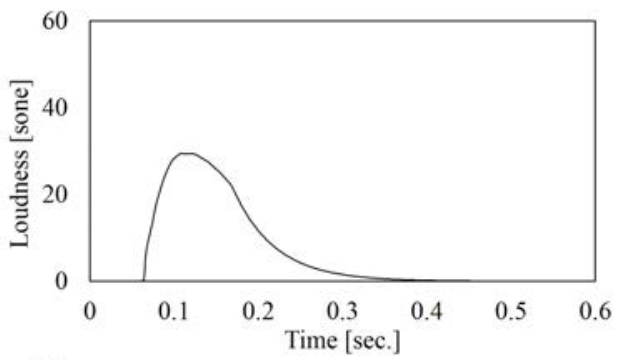

(c)

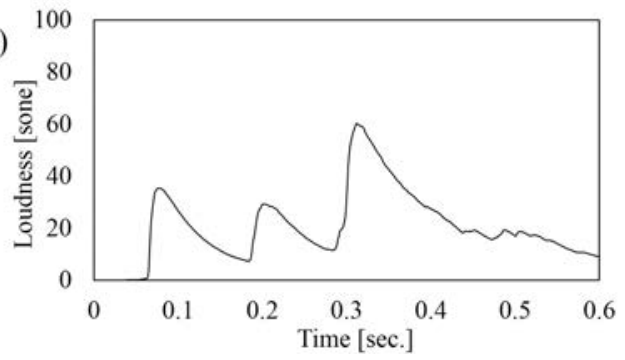

(b)

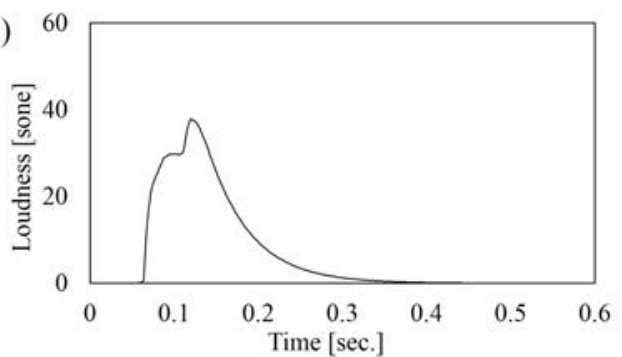

(d)

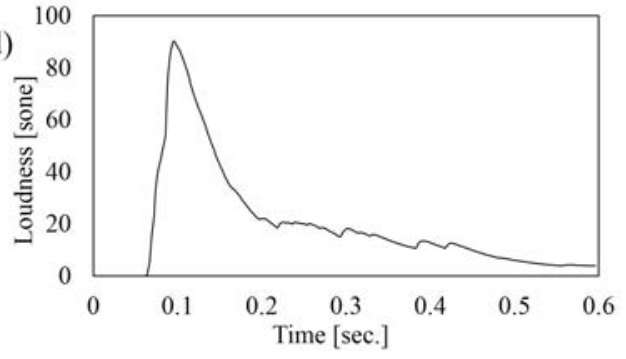

Figure 12: (a) Loudness waveform of the pop sound for sample can B, (b) loudness waveform of the pop sound for sample can J, (c) loudness waveform for the tearing sound of sample can B, and (d) loudness waveform for the tearing sound of sample can J. The waveform in (c) is an example of a curve with multiple peaks, and that in (d) is a curve with a single peak.

and $\mathrm{K}$, and four for sample D. However, the appearance and amplitude of these maxima showed no similarity.

2. The tearing sound is a large proportion of the total duration of the can-opening sound.

3. Sharpness and peak frequency analyses of the opening sounds of sample cans B, D, I, and K found no significant features.

\subsection{Extraction of the characteristic features of an objective sound}

In this section, we discuss how the results of the sensibility evaluation correlate with the physical test results. Their association was evaluated by calculating correlation coefficients for all possible combinations of sensibility factors and physical parameters, as shown in Table 3. The correlation coefficients whose values were greater than 0.5 had a statistical significance of $5 \%$. Because can-opening sounds with a high texture factor score were more likely evaluated as having the objective sound, the factor was found to be positively correlated with the duration of the tearing sound $\left(T_{\mathrm{t}}\right)$, and, thus, it is thought that $T_{\mathrm{t}}$ strongly affects the texture factor. In addition, physical 
Table 3: Correlation coefficients between sensibility factors and physical parameters.

\begin{tabular}{cccc}
\hline & Strength & Texture & Comfort \\
\hline$L_{\mathrm{p}}$ & 0.539 & -0.160 & 0.443 \\
\hline$L_{\mathrm{t}}$ & 0.132 & -0.212 & 0.224 \\
\hline$S_{\mathrm{p}}$ & -0.198 & 0.048 & -0.085 \\
\hline$S_{\mathrm{t}}$ & 0.506 & -0.144 & 0.452 \\
\hline$f_{\mathrm{p}}$ & -0.169 & -0.281 & 0.057 \\
\hline$f_{\mathrm{t}}$ & 0.033 & -0.097 & 0.591 \\
\hline$T_{\mathrm{p}}$ & -0.470 & -0.190 & -0.417 \\
\hline$T_{\mathrm{t}}$ & 0.145 & 0.527 & 0.264 \\
\hline
\end{tabular}

evaluation revealed that the can-opening sounds whose tearing part consisted of several local peaks and was a large proportion of the total duration of the can-opening sound were the closest approximation of the objective sound. The sample cans B, D, I, and K had such characteristics in their sound that could leave an easy-to-open, comfortable impression on users. However, because the correlation between the peak loudness of the tearing sound $\left(L_{\mathrm{p}}\right)$ and the texture factor is statistically insignificant, qualitative evaluation should focus on another aspect of the loudness waveform. Furthermore, cans B, D, $\mathrm{I}$, and $\mathrm{K}$ have medium-sized openings, another feature that could be taken into consideration to realize the objective can-opening sound.

Among the four statistically significant correlation values, the correlation between $f_{\mathrm{t}}$ and the comfort factor was the largest. Positive correlation means that the comfort factor values become large for higher frequency values, while on the other hand, the factor values become small or negative for lower frequency values. Most of these peak frequencies were found in the frequency responses as the dominant peaks. Although it was found from the subjective analysis that the comfort factor was less likely to correlate with the objective sound, a distinct high-frequency sound might have caused respondents a comfortable feeling.

\section{Conclusions}

In this study, we suggested a design procedure for realizing the target of a pleasant can-opening sound. The design's goal was "a sound that brings to the user an easy-to-open, comfortable feeling with sureness." First, the 
sensibility was evaluated by male university students using a semantic differential scale method to give their impression of the can-opening sound. Three sensibility factors, i.e., strength, texture, and comfort, which characterize the can-opening sounds on a psychological level, were derived from the sensibility evaluation. Second, the physical properties were evaluated in both time and frequency domains. The can-opening sound usually consists of a pop sound followed by a tearing sound. The tearing part is important for the realization of the objective sound defined above. The sensibility and physical property evaluations were followed by a correlation analysis between the psychological and the physical parameters. The physically alterable design parameters of the cans were determined to achieve the design goal of a comfortable sound. For the can-opening sound to become the target sound, it is essential that the texture factor has a high score. Sounds with a high texture factor have more than one peak in the loudness time-history waveform, and duration of the tearing sound is a relatively large proportion of the total duration of those sounds compared to that of a group of sounds with a low texture factor score.

It is considered that the above-mentioned physical properties of the sound are influenced by the thickness of the panel, the geometry and residual thickness of the scores, the contact between the tab and the panel, and so on. These characteristics can be correlated with the physical properties of sound. Since it was shown that the physical sound properties were correlated with sensibility factors, we can indirectly associate the product design parameters to the sensibility factors. Accordingly, the design parameters can be inversely determined by reference to the correlation with the sensibility features of the objective sound. Therefore, in the future can designing, factors contribute to the objective sound will be taken into consideration.

\section{Acknowledgements}

The authors declare that there are no known conflicts of interest associated with this publication and there has been no significant financial support for this work that could have influenced its outcome.

\section{Author Contributions}

All of the authors contributed equally to this work. 


\section{References}

[1] Ohtomi K, Hosaka R, Yanagisawa H, Murakami T. Product sound design for diverse customer's kansei. In: Proceedings of the Internoise 2009; 2009. p.3039-47.

[2] Parizet E, Guyader E, Nosulenko V. Analysis of car door closing sound quality. Appl Acoust 2008;69:12-22. doi:10.1016/j.apacoust.2006.09.004

[3] Bezat M, Kronland-Martinet R, Roussarie V, Ystad S. From acoustic descriptors to evoked quality of car door sounds. J Acoust Soc Am 2014:136;226-41. doi:10.1121/1.4883364

[4] Toi T, Kazahaya S. Sound quality improvement on transient sound generated by operating shutter of camera based on mechanism design. In: Proceedings of the Internoise 2003; 2003. p.4556-61.

[5] Harris CM. Handbook of Acoustical Measurements and Noise Control. 3rd ed. New York: McGraw-Hill; 1991.

[6] Ozcan E, van Egmond R. Basic semantics of product sounds. Int J Design 2012:6;41-53.

[7] Susini P, McAdams S, Winsberg S, Perry I, Vieillard S, Rodet X. Characterizing the sound quality of air-conditioning noise. Appl Acoust 2004:65;763-90. doi:10.1016/j.apacoust.2004.02.003

[8] Jeon JY, Ho JY, Chang HY. Sound radiation and sound quality characteristics of refrigerator noise in real living environments. Appl Acoust 2007:68;1118-34. doi:10.1016/j.apacoust.2006.06.005

[9] Han J, Yamazaki K, Itoh R, Nishiyama S. Multi-objective optimization of a two-piece aluminum beverage bottle considering tactile sensation of heat and embossing formability. Struct Multidiscip Optimization 2006:32;141-51, doi:10.1007/s00158-005-0563-8

[10] Han J, Nishiyama S, Yamazaki K, Itoh R. Ergonomic design of beverage can lift tabs based on numerical evaluations of fingertip discomfort. Appl Ergon 2008:39;150-7, doi:10.1016/j.apergo.2007.05.010 
[11] Ito R, Yamazaki K, Han J. A study on openability of an aluminum beverage bottle. Trans Jpn Soc Mech Eng Ser C 2008:74;475-83, doi:10.1299/ kikaic.74.475

[12] Chihara T, Yamazaki K, Itoh R, Han J. Evaluation of drinking ease relative to the opening diameter and beverage type of aluminum beverage bottles. J Food Eng 2009:95;264-71. doi:10.1016/j.jfoodeng.2009.05.006

[13] Osgood CE. Semantic differential technique in the comparative study of cultures. Am Anthropol 1964:66;171-200.

[14] Kitamura O, Futai S, Kuriyama J, Masuda N. Extraction of the tonal factors in sounds examined for youths in 50's of Showa period in Japan. Trans Tech Comm Psychol Physiol Acoust 1978:H-51-11.

[15] Hair JF, Black WC, Babin BJ, Anderson RE. Multivariate Data Analysis. 7th ed. New Jersey: Pearson Prentice-Hall; 2009.

[16] Cabrera D, Ferguson S, Schubert E. PsySound3: software for acoustical and psychoacoustical analysis of sound recordings. In: Proceedings of the 13th International Conference on Auditory Display; 2007. p.356-63.

[17] ISO532: Acoustics- Method for calculating loudness level; 1975. Available online: http://www.iso.org/iso/catalogue_detail.htm?csnumber $=4603$ (accessed on 1 May 2015).

[18] Zwicker E. Subdivision of the audible frequency range into critical bands. J Acoust Soc Am 1961:33;248. 